Drevland F., and Klakegg O. J. (2017). “A Taxonomy of Client Product Value in Construction Project” In: LC3 2017 Volume II - Proceedings of the 25th Annual Conference of the International Group for Lean Construction (IGLC), Walsh, K., Sacks, R., Brilakis, I. (eds.), Heraklion, Greece, pp. 491-498. DOI: https://doi.org/10.24928/2017/0292

\title{
A TAXONOMY OF CLIENT PRODUCT VALUE IN CONSTRUCTION PROJECTS
}

\author{
Frode Drevland ${ }^{1}$ and Ole Jonny Klakegg ${ }^{2}$
}

\begin{abstract}
The goal of construction projects is to deliver value for the customers. In this paper, we look at what is valuable to one of those, the paying client.

Classification schemes, such as taxonomies and typologies, are in many fields used to better understand the terrain in which one is operating. We argue that having such as scheme for the client value in construction projects would be beneficial for better understanding what is valuable for the client. In this paper, we present one that has been made using abductive reasoning based on a scoping study of relevant literature.

The paper starts out by presenting different kinds of classification schemes and their characteristics. Then, a set of guiding principles for value classification schemes are introduced, followed by a critique of existing classification schemes considering these. Afterwards, a taxonomy of client value is presented with the reasons for the chosen breakdown structure. Finally, the goodness and completeness of the taxonomy is discussed.
\end{abstract}

Keywords: Lean construction, Value, value taxonomy.

\section{INTRODUCTION}

The goal of construction projects is to deliver value for the customers. While construction projects can be said to have many customers (Drevland and Lohne 2015), we will in this paper limit ourselves to considering value for the paying clients and what is valuable for them. However, to be able to consider what is valuable, we first need a clear notion of the concept of value.

As a concept, value is ill-defined (Salvatierra-Garrido et al. 2012) without any commonly agreed upon definition (Thyssen et al. 2010). The most common definition of value in the general literature pertaining to construction projects, is that it is the relationship between what you give and what you get (Kelly et al. 2004). However, within the Lean Construction community there is a clear tendency to use the term value referring only to the get, or benefit, side (Drevland and Lohne 2015). In this paper, our understanding of value is in accordance with Drevland and Lohne (2015). They give a comprehensive, but rather lengthy definition of value, however, the essence of it can be said to be that value is the result of an evaluative judgment of what you get and what you give.

Based on the above we will postulate that delivering value to the client in a construction project is about arriving at an optimal balance of what they get and what they give. Value is particular (Drevland and Lohne 2015), i.e. is must always be considered from the point of view of someone. This being the case entails that different clients with

1 Assistant Professor, NTNU - Norwegian University of Science and Technology, Trondheim, Norway, +4792064262, frode.drevland@ntnu.no

2 Professor, NTNU - Norwegian University of Science and Technology, Trondheim, Norway, ole.jonny.klakegg@ntnu.no 
different purposes will have different things that they care about regarding what is important to them and how they weight different get and give aspects. However, there are some commonalities, e.g. construction cost will always be an issue.

Classification schemes, such as taxonomies and typologies, are in many fields used to better understand the terrain in which one is operating. We would argue that having such as scheme for the get and give factors that come into play for the clients' value judgement in construction projects would be beneficial. Partially, to further general understanding of value for both practitioners and clients, but also to serve as a foundation for developing tools for optimizing value delivery as well as for analysing current practice.

Although there does already exists some classification schemes like this, we have found them to fall short in one way or the other. In this paper we therefore set out to develop a taxonomy of client value that can serve this purpose, i.e. to create a generic classification scheme for the get and give factors that are important to client of construction projects. However, we set out to do this with some limitations.

With regard to building types, buildings broadly fall into two categories; residences and production assets (Blakstad et al. 2008). We believe that there is a great deal of overlap in the get and give factors that are considered for these two categories of buildings. However, to avoid making the discussion overly complex we initially limit ourselves to consider buildings that will be employed as production assets. Thus, our goal in this paper is to succinctly present a taxonomy of value from the point of view of clients of nonresidential buildings. Furthermore, we also limit ourselves initially to consider clients that are building for their own use. This is again done to avoid making the explanations and discussions overly complex.

Regarding factors, we limit ourselves to considering those factors that are directly influenced by the construction project and that are tied to the product delivered. I.e. some of the get and give factors in a construction project will be tied to the process rather than the product, e.g. clients cost of staffing for managing the process, and some of the get and give consequences will be outside of the scope of the building projects, e.g. the loss of other investments opportunities. Furthermore, we do not explicitly include factors that are related to financing and taxation of the built asset, even though they might be directly influenced by the project.

\section{TAXONOMIES, TYPOLOGIES AND CLASSIFICATIONS}

There are several differing definitions of the terms typology and taxonomy. In his seminal work on taxonomies and typologies in the social sciences, Baily (1994) claims typology and taxonomy are used interchangeably by many people. Baily himself defines typology as being classification based on concepts while taxonomy is based on empirical data. However, these definitions do not correspond well with the different value classification schemes we have found in literature. We found definitions by Marradi (1990) to be more in accordance with these.

Classification can be said to be about ordering entities into groups or classes based on their properties (Bailey 1994). According to Marradi (1990), the difference between the types of classification scheme the lies in how this grouping is done. An adapted version of Marradi's definition is shown in Table 1. 
Table 1: Classification types. (Based on Marradi 1990)

\begin{tabular}{ccc}
\hline Classification type & Criteria use & Structure \\
\hline Simple classification & Only one & Flat \\
Typology & Multiple simultaneously & Multi-dimensional matrix \\
Taxology & Multiple in succession & Hierarchical \\
\hline
\end{tabular}

\section{METHOD}

The problem of creating a classification scheme has been attacked using a pragmatic research approach. Within the pragmatic paradigm "inquiry aims at utility for us rather than an accurate account of how things are in themselves" (Rorty 1999). Thus, we have not tried to develop the one true taxonomy of value in positivistic sense, but rather to create something that is useful for our stated purposes.

To construct the taxonomy we first undertook a scoping study, as described by Arksey and O'Malley (2005), to identify relevant literature. Here, we looked not only for literature specifically discussing value in construction projects, but also for literature from other fields that deals customer value of products.

Based on the intended use of the classification scheme, as well our understanding of value grounded in Drevland and Lohne's (2015) nine tenets on the nature of value, we set forth four guiding principles (presented in section 5).

Of the possible classification schemes listed in table 1, we considered a taxonomy to be the best model for client value factors in construction projects. The primary reason for this is that taxonomies are more flexible with regards to extensibility. I.e. it's hierarchical nature means that the factors can always be detailed more if need be.

Based on the identified literature, the selected classification scheme type, and the guiding principles set forth, abductive reasoning was used to arrive at the taxonomy presented in section 6 .

\section{GUIDING PRINCIPLES FOR CLASSIFICATION STRUCTURE}

We would argue that the primary benefit of having a classification of value factors is that it will ease the decision making process in projects by making it easier to understand how decisions impact the value for the client. Decisions that impact client value will tend to involve a trade-off between different get and give factors. It is therefore important that the taxonomy is made in such a way that it facilitates the consideration of trade-offs. To do so we believe that the following principles must be satisfied.

P1 The classification scheme must contain all relevant factors

P2 Factors should be mutually exclusive

P3 The classification scheme must be detailed enough for trade-offs to be considered

According to Drevland and Lohne (2015), "get and give consequences are always in the form of gained or lost experiences, or expressed in monetary terms as a placeholder for experiences". What this in essence means, in the terms of a classification scheme, is that all the get and give factors must be ends in and of themselves. Therefore, a fourth principles is:

P4 Factors must be ends - not means 


\section{SHORTFALLS OF EXISTING CLASSIFICATION SCHEMES}

The literature review identified many sources that consider mapping value in projects through workshop approaches etc. , however, few sources that proposed any kind of generic taxonomy applicable to all construction projects. It is unfortunately not possible to fully describe and critique these classification schemes within the limits of this paper. However, some general observations regarding common shortcoming are in place.

Shchemes using the Vitruvian values of firmitas (solidity, durability), utilitas (utility) and venustas (beauty, delight) as a basis (e.g. Construction Industry Council 2002; Emmitt et al. 2005) are flawed per the third principle we set forth. This is expounded further upon in the discussion section of this paper (see also Drevland and Svalestuen 2013).

Another issue relates to not being sufficiently detailed. Examples of these are Drevland and Svalestuen (2013) and Emmit (2005). However, it should be pointed out that Emmitt does not pretend to present a fully develop generic classification scheme, but rather a starting point for a workshop based value mapping approach.

\section{TAXonomy of Client Product VAlue}

Figure 1 shows the taxonomy that was developed. The top level division is based on phases of the buildings lifecycle, originally suggested by Drevland and Svalestuen (2013). The rest of this section details each of the levels and categories, below the top level, and the reasoning behind them.

Note that for taxonomies an 'other' category is nominally present at every level. We have chosen to omit this to simplify the taxonomy for this paper. However, for practical use this should be considered. Furthermore, many of the factors included here are typically cost only. However, that might always not be the case. The building operations factors will traditionally be all give or cost related. E.g. the advent of energy-plus-houses could entail building will produce more energy than it uses, thereby energy could become a get rather than a give. For this reason, none of the factors has been labelled as cost or benefit.

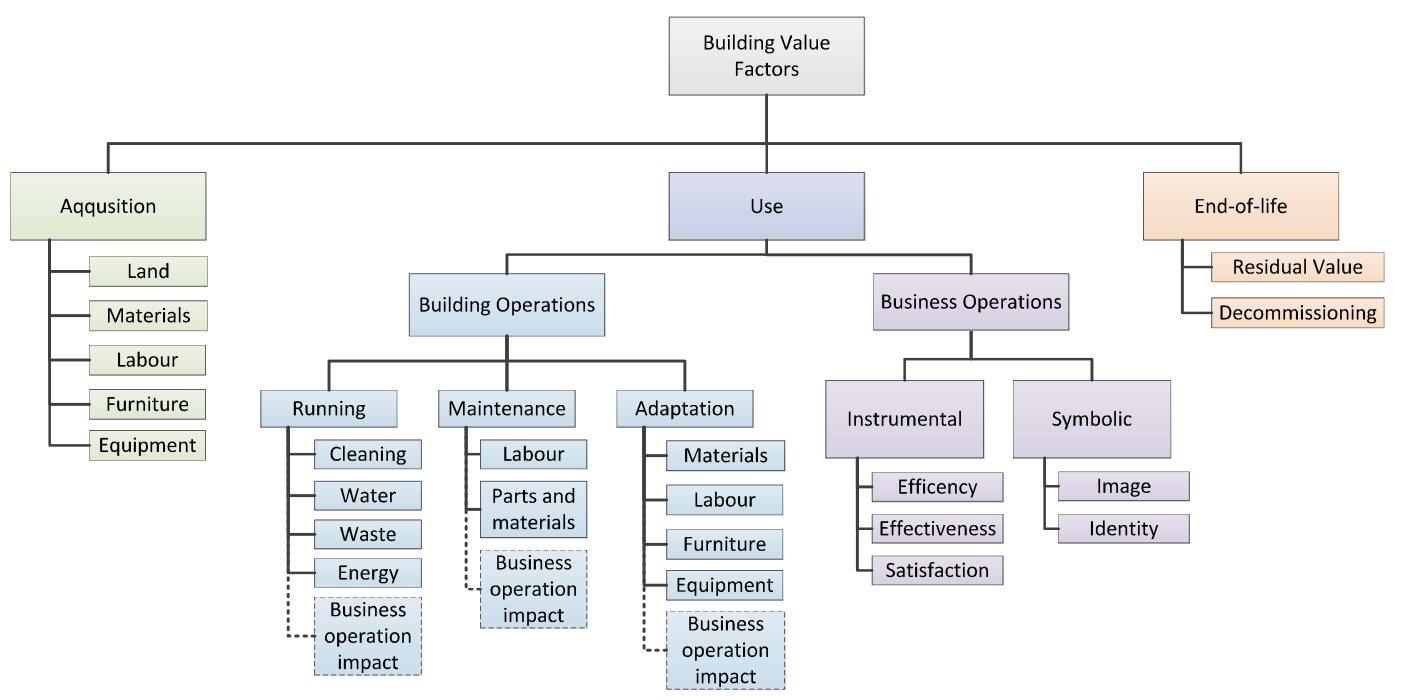

Figure 1 Taxonomy of client value in construction projects 


\subsection{Acquisition}

During the acquisition phase, the building does not normally provide any Get or benefits for the client (Drevland and Svalestuen 2013). The Give side are related to the cost of constructing the building and acquiring the land the land it will stand on and the furniture and equipment that will be in it (Construction Industry Council 2002). Any further detailing if these factors would be dependent on the particularities of the location and the project, and are left at this level.

\subsection{Use}

The major distinction to be made in the use phase are the between factors pertaining to building operations and business operations. Building operations factors are related to the operation and maintenance of the building, while business operations factors are related to the operation of the business that housed by the building.

\subsubsection{Business operation}

From a business perspective, the purpose of a building is be an enabling infrastructure, to support the business processes of the entities they house (Mahal 2010). In this sense buildings provide both an Instrumental and Symbolic get (or possibly give) (Eikeland 1998). Instrumental in the sense that building directly supports the production process that take place in the building and symbolic in the sense that the building provides image and identity for the business that occupy the building. Image being how the outside world sees the business while Identity is how the organization and its employees sees itself.

The instrumental side of this branch is in essence about the fitness for purpose of the building, or usability, which is the term commonly used in the research literature (Blakstad et al. 2008; Leaman et al. 2010). The term originated in the ICT industry and is in ISO 9241-11 defined as the "extent to which a product can be used by specified users to achieve specific goals with effectiveness, efficient and satisfaction in a specified context of use" (ISO 1998). Furthermore, effectiveness is the "accuracy and completeness which users can achieve specified goals", efficiency is a measure of the "resources expended in relation to the accuracy and completeness with which users achieve goals", and finally, satisfaction is "freedom from discomfort, and positive attitudes towards the use of the product".

\subsubsection{Building operations}

On the building operations side, Running and Maintenance should be pretty selfexplanatory. Adaptation, on the other hand, warrants some further explanation.

Businesses grow and evolve while technology and society changes. With this a business's business model and processes changes as well. This will often entail that the building enabling the business processes have to be changed as well. With the exception of the last factor, all the factors are tied to modifying the building so that it will be able to properly support the changed business model and processes.

The last factor found under all three of Running, Maintenance, and Adaptation is Business operation impact. Maintenance and adaption of a building, as well as some running activates like cleaning, will to a lesser or greater extent impact the business operations taking place in the building. E.g. a room becomes unusable while it is being worked upon. The Business operation impact factors are drawn with dotted lines in the taxonomy. The reason for this is that they strictly speaking overlap with the business operations factors. This discussed more in depth in discussion section of the paper. 


\subsection{End-of-Life}

At some point in time the building will either no longer be able to support the current business model sufficiently, or the owner changes to different business model, and the building becomes obsolete. The building could then hold some Residual value for the owner. Either if they reuse the facility themselves for other purposes or by selling it to another party.

Decommisioning refers to all get and give that is incurred by the owner the current activity is ended. E.g. the cost of removing equipment etc. and possibly demolition of the facility if it has no other use. The latter will be substantial if the facility to be demolished for example contains hazardous waste; e.g. demolishing a nuclear power plant will be very expensive due to the requirements imposed on waste and material handling and storage.

\section{DISCUSSION}

\subsection{The issue of time}

The biggest challenge in making a taxonomy for value factors for buildings is how to handle the time aspect of value. This is something is that immensely more difficult for buildings than for most other products because of their long lifetime. E.g. compared to building a car. If someone buys a sports car when they are young, they do not try and convert it to a minivan when they grow older, get married, and have kids. They sell their sports car and buy a new minivan. Buildings, however, do get adapted over time as the needs of the owners change.

Most of the get and give of a building comes over time. Thus, each of the factors can be said to be functions of time. This is in and of itself not a problem. At least not if the factors are considered on their own in a static context. E.g. assessing the energy consumption and expenditures of building over its lifetime is relative straight forward, if we assume the same activity for all future.

The challenge comes when we have to consider how the factors correlate with or impact each other. Say we want to reduce the maintenance cost of a building by putting in more durable floor coverings. This affects not only the maintenance factors, but also the acquisition factors. However, since acquisition can basically be considered a single point in time in this context, this is still a very manageable situation. It easy to estimate and adjust the cost of labour and materials for putting the different type of floor covering at the time of construction. On her hand, it is a lot more difficult to assess the impacts to the business operations.

This is the reason why we chosen to put business operation impact factors for each to building operation branches. We believe it is a lot easier to directly estimate the impact than it is to adjust the business operations factors to take into account the impact these activities will have at certain points during the buildings life time. This, however, depends on what kinds of tools are being used. Our mind-set has been that this taxonomy should be useable in conjunction with relatively simple tools like Choosing by Advantages (CBA). Of course, if one where to develop computerized tools backed by algorithms that can abstract away the complexity of these relationships, it would preferable to not have this overlap.

\subsection{Goodness of taxonomy}

The taxonomy was made using abductive reasoning on the basis of a literature review. While we are reasonably certain that the upper levels of the taxonomy are good and 
sensible, it might very well be that the detailing at the lower levels should be tweaked to make the taxonomy more easily usable in practice. This, however, is a question that can only be answered from empirical testing.

Furthermore, we would like to note that our purpose has not been to develop a definite value taxonomy; the end all and be all of what constitutes client value in construction templates. Rather, the taxonomy should rather be considered a starting point or template for developing tools for practical use.

\subsection{Completeness of taxonomy}

We initially state four principles for the design of the taxonomy. One of which was the taxonomy must contain all relevant factors. We do believe this to be the case. There is however an important caveat to this, the client's values might dictate other factors to be added. Let us consider the case were one of the core values of the client is to preserve planet earth. In this case they might want a green building even though it might be more expensive and yield no positive effect on the business operations factors. In this case the taxonomy should rightfully be expanded to take into account the client's values.

Many of the value classification schemes we came across used the Vitruvian values of firmitas (solidity, durability), utilitas (utility) and venustas (beauty, delight) as a basis. We believe most will recognize that utilitas is well covered in the taxonomy, but what about the other two aspects? The problem with including them directly is that they violate the third principle we laid down, that the factors must be and ends in and of itself.

Beauty has no intrinsic value (Drevland and Lohne 2015). The aesthetics of a building is a means to either 1) Efficiency - i.e. patients getting well faster in a hospital (Rybkowski 2009), 2) Satisfaction, - the business customers and employees become more satisfied in their interactions with the building, 3) Image - the outside gets a more favourable image of the business housed by the building, or 4) Identity - The building helps foster the desired identity of the organization it houses,

A similar argument can be made for firmitas. The reason for making a building more solid and durable is to make it able to support the Business operations over longer timespan, i.e. related to the factors being a function of time, and/or to reduce the costs of the Running and Maintenance of the building.

\section{CONCLUSION}

We have in this paper presented a taxonomy of client product value that has been developed form a theoretical basis. We believe it can be of help in construction projects by making it easier to understand how decisions impact the value for the client, and could provide a framework for tools used in this context. In this sense, the taxonomy should not be considered a definitive answer, but rather a template to adjusted to serve one's purpose. However, we would argue that the four principles presented in section 5 must always be observed.

With regards to further research, the taxonomy will serve as a part of analytical framework to analyse the value delivery processes in practice in projects. I.e. to answer questions such as to what extent are these factors considered, how is prioritizing between the factors done, how is the project process shaped to achieve an optimal balance? 


\section{REFERENCES}

Arksey, H., and O’Malley, L. (2005). "Scoping studies: towards a methodological framework." International Journal of Social Research Methodology, 8(1), 19-32.

Bailey, K. D. (1994). Typologies and Taxonomies: An Introduction to Classification Techniques. Sage Publications, Thousand Oaks, Calif.

Blakstad, S. H., Hansen, G. K., and Knudsen, W. (2008). "Methods and tools for evaluation of usability in buildings." Usability of Workplaces, Phase, 2.

Construction Industry Council. (2002). How Buildings Add Value for Clients. ICE Publishing.

Drevland, F., and Lohne, J. (2015). “Nine Tenets on the Nature of Value." 23rd Annual Conference of the International Group for Lean Construction, Perth, Australia, 475485.

Drevland, F., and Svalestuen, F. (2013). "Towards a framework for understanding and describing the product value delivered from construction projects.”21th Ann. Conf. of the Int'l. Group for Lean Construction, Fortaleza, Brazil.

Eikeland, P. T. (1998). Teoretisk analyse av byggeprosesser. Samspillet i Byggeprosessen, Trondheim.

Emmitt, S., Sander, D., and Christoffersen, A. K. (2005). "The Value Universe: Defining a Value Based Approach to Lean Construction.” 13th Ann. Conf. of the Int'l. Group for Lean Construction, Sydney, Australia.

ISO. (1998). “9241-11.” Ergonomic Requirements for Office Work with Visual Display Terminals (VDTs)-Part II Guidance on Usability.

Kelly, J., Male, S., and Graham, D. (2004). Value Management of Construction Projects. Wiley-Blackwell.

Leaman, A., Stevenson, F., and Bordass, B. (2010). "Building evaluation: practice and principles.”Building Research \& Information, 38(5), 564-577.

Mahal, A. (2010). How Work Gets Done: Business Process Management, Basics and Beyond. Technics Publications, LLC.

Marradi, A. (1990). “Classification, typology, taxonomy.” Quality and Quantity, 24(2), 129-157.

Rorty, R. (1999). Philosophy and Social Hope. Penguin.

Rybkowski, Z. K. (2009). "The Application Of Root Cause Analysis And Target Value Design To Evidence-Based Design In The Capital Planning Of Healthcare Facilities." University of California, Berkeley, Berkeley.

Salvatierra-Garrido, J., Pasquire, C., and Miron, L. (2012). "Exploring value concept through the iglc community: Nineteen years of experience." 20th Ann. Conf. of the Int'l. Group for Lean Construction, San Diego, CA, USA.

Thyssen, M. H., Emmitt, S., Bonke, S., and Kirk-Christoffersen, A. (2010). "Facilitating Client Value Creation in the Conceptual Design Phase of Construction Projects: A Workshop Approach.” Architectural Engineering and Design Management, 6(1), 1830 . 